\title{
STUDY OF OVERALL AND LOCAL ELECTROCHEMICAL RESPONSES OF OXIDE FILMS GROWN ON COCr ALLOY UNDER BIOLOGICAL ENVIRONMENTS
}

I. Diaz , J.F. Martinez-Lerma², R. Montoya ${ }^{1,3}$, I. Llorente, M.L. Escudero, M.C. García-Alonso ${ }^{1,{ }^{*}}$

${ }^{1}$ Centro Nacional de Investigaciones Metalúrgicas (CENIM), Consejo Superior de Investigaciones Científicas (CSIC), Avenida Gregorio del Amo, 8, Madrid, Spain

${ }^{2}$ Facultad de Ciencias Químicas, Universidad Autónoma de San Luís Potosí, S.L.P. Av. Dr. Manuel Nava No. 6, Zona Universitaria, C.P. 78210. San Luis Potosí, S.L.P., México.

${ }^{3}$ present address: Research Group Electrochemical and Surface Engineering. Vrije Universiteit Brussel. Campus Etterbeek Pleinlaan 2, 1050 Brussels

*crisga@cenim.csic.es

\section{Abstract}

The interaction of the physiological medium and living tissues with the implant surfaces in biological environments is regulated by biopotentials that induce changes in the chemical composition, structure and thickness of the oxide film. In this work, oxide films grown on $\mathrm{CoCr}$ alloys at $0.5 \mathrm{Vvs} \mathrm{Ag} / \mathrm{AgCl}$ and $0.7 \mathrm{Vvs} \mathrm{Ag} / \mathrm{AgCl}$ have been characterized through overall and localized electrochemical techniques in a phosphate buffer solution and $0.3 \%$ hyaluronic acid. Nanopores of 10-50 nm diameter are homogeneously distributed along the surface in the oxide film formed at $0.7 \mathrm{Vvs} \mathrm{Ag} / \mathrm{AgCl}$. The distribution of the Constant Phase Element studied by local electrochemical impedance spectroscopy showed a three-dimensional (3D) model on the oxide films grown at $0.5 \mathrm{Vvs} \mathrm{Ag} / \mathrm{AgCl}$ and $0.7 \mathrm{Vvs} \mathrm{Ag} / \mathrm{AgCl}$. This behaviour is especially noticeable in oxide films grown at $0.7 \mathrm{Vvs} \mathrm{Ag} / \mathrm{AgCl}$, probably due to surface inhomogeneities, and resistive properties generated by the potentiostatic growth of the oxide film.

Keywords: CoCr implant; EIS; LEIS; Hyaluronic acid; CPE distribution 


\section{INTRODUCTION}

The kinetics of the dissolution and formation of the passive film on $\mathrm{CoCr}$ alloys in the physiological fluids are mainly influenced by factors such as the type and chemical composition of the alloy [1], long-term exposure to aggressive ions $[2,3,4,5,6], \mathrm{pH}$ changes and temperature of the biological environment. However, this is not only inherent to the interaction of physiological medium with the surface but also to the electrical interactions induced by the living tissues, known as biopotentials. In vivo biopotentials control the normal growth and development of cells and tissues inducing a continuous stimulation of the metallic surface.

The insertion of permanent joint replacements activates injury potentials that alter the stable potential patterns of intact tissue after trauma and during healing. At this period, currents of about $1-100 \mu \mathrm{A} / \mathrm{cm}^{2}$ can be measured in injured tissues that imply, considering the resistivity of soft tissues as $100 \Omega$, electric fields of $1-10 \mathrm{mV} / \mathrm{cm}$ [7]. Bone tissue has a piezoelectric behaviour (i.e., electric potential in response to applied forces) that can modify the electrochemical potential of the metallic implants. The physiological environment in combination with constant cyclic loading on the implants, such as wear-corrosion phenomena and micromotion or fretting-corrosion, favours the activation of the passive film as a consequence of the continuous activation/repassivation cycles [8]. These continuous and dynamic processes not only weaken the surface performance but also lead to an increase in the debris around the implant. To date debris produced in in vivo wear-corrosion from articulating surfaces has been identified as one of the most important phenomenon causing the failure of the implant. It is interesting not to forget that the electrical implications of corrosion and its effect on the surrounding tissue can be strongly important on the bone healing. Bone cells are sensitive to electrical signals, stimulating or inhibiting the activity of osteoblast or osteoclast cells and, consequently, breaking the balance between both [9]. Therefore, from the point of view of the implant, a wide potential range is imposed on the surface not only created by the physiological medium $(\mathrm{pH}$, nature and concentration of ion, etc.) but also by that generated by the live tissue.

All these biochemical factors favour several processes on the surface of the metallic implants: slow diffusion of metal ions through the passive film; dissolution and/or growing of the oxide film under high oxidizing conditions, caused by the debris products from cell metabolism 
and/or the polarization arising from living tissues; and, local breakdown of passivity, due to pitting or crevice corrosion enhanced by the changing $\mathrm{pH}$ values and nature of aggressive ions. All of them offer a wide electrochemical potential range occurring in the implantation site on the metallic biomaterial.

In this work, overall and localized electrochemical techniques have been used to characterize the oxide films grown on the CoCr alloy under potentials whose current densities are similar to those reported for injured tissues $\left(1-100 \mu \mathrm{A} / \mathrm{cm}^{2}\right)$. In an attempt to simulate as closely as possible, the real situation of healthy joints [10], the authors have chosen a phosphate buffer solution with $0.3 \%$ hyaluronic acid as an electrolyte for the tests. In the literature many solutions have been used to simulate in vivo conditions and identify their tribological roles on artificial joints. The major difference between synovial fluid (SF) and other body fluids derived from plasma is its high content of protein and the presence of hyaluronic acid, which is the main component of SF and is a known joint lubricant.

\section{MATERIALS AND METHODS}

\section{Material}

The CoCr alloy with high carbon content supplied by BIOMET Spain Orthopaedics (Valencia), following standard ASTM F75 (Table 1), was used. This alloy was supplied as a disk $38 \mathrm{~mm}$ diameter and $4 \mathrm{~mm}$ thick, as "double heat-treated" samples, i.e. solution treatment (ST) followed by hot isostatically pressing (HIP). The sample preparation consisted of grinding on SiC paper from mesh 400 to mesh 1200 , followed by mechanical polishing with $3 \mu \mathrm{m}$ diamond paste, ultrasonic cleaning in alcohol and deionized water successively and then air dried.

\section{Corrosive media}

The aqueous medium used as electrolyte was based on the Phosphate Buffer Solution: $0.2 \mathrm{~g} / \mathrm{L} \mathrm{KCl}, 0.2 \mathrm{~g} / \mathrm{L} \mathrm{KH}_{2} \mathrm{PO}_{4}, 8 \mathrm{~g} / \mathrm{L} \mathrm{NaCl}$ and 1.150g/L Na $2 \mathrm{HPO}_{4}$ (anhydrous) (PBS) adding 0.3\% hyaluronic acid (hereafter PBS-HA). The concentration of hyaluronic acid for the overall electrochemical measurements (DC and $A C$ techniques) was $0.3 \%$, in agreement with the range reported for healthy joints [10] simulating the synovial fluid. This solution was diluted 10 times for local impedance measurements. The motivation for using a reduced concentration for the local 
impedance measurements was the decrease of the current resolution at high conductivity values of the electrolyte.

\section{Overall electrochemical techniques}

All electrochemical experiments such as the measurement of the corrosion potential (Ecorr), Electrochemical Impedance Spectroscopy (EIS), chronoamperometry and anodic polarization curves were conducted in a three-electrode cell connected to a Gamry Instrument Potentiostat/Galvanostat/FRA (Reference 600). An $\mathrm{Ag} / \mathrm{AgCl}(\mathrm{NaCl} 3 \mathrm{M})$ electrode was used as the reference electrode, a platinum wire as the counter electrode and the $\mathrm{CoCr}$ alloy $\left(0.78 \mathrm{~cm}^{2}\right)$ as the working electrode. Electrochemical tests were performed in triplicate and the Ecorr was previously measured for 1 hour to obtain the stabilization before the application of potentials far from the stationary state.

Single sweep potentiodynamic polarization curves were performed at $10 \mathrm{mV} / \mathrm{min}$ scanning rate from the Ecorr up reaching a potential of $1 \mathrm{~V}$ in the noble direction, which is considered approximately as the maximum potential that a metallic biomaterial can reach in the human body [11]. Then, a reverse scan was applied until reaching the protection potential. The passivation currents, $I_{p}$, and breakdown potentials, Ebd, were obtained.

The chronoamperometric test was performed by applying potentials for $3600 \mathrm{~s}$. Two different potentials $(0.5 \mathrm{Vvs} \mathrm{Ag} / \mathrm{AgCl}$ and $0.7 \mathrm{Vvs} \mathrm{Ag} / \mathrm{AgCl})$ from the anodic polarization curves were chosen.

The EIS tests were performed on the previously polarized samples at the Ecorr by applying a sinusoidal wave of $10 \mathrm{mV}$ amplitude at a frequency range from $10^{5} \mathrm{~Hz}-10^{-1} \mathrm{~Hz}$, spaced logarithmically (five per decade). The EIS results were analysed by fitting the experimental impedance data with the properly electrical equivalent circuit. The parameters of the electrical equivalent circuit were calculated by fitting the impedance function to the measured spectra using a non-linear least-squares program (NLLS program) with Z-plot/Z-view software. The criteria used to estimate the quality of the fitting were the lowest chi-square value $\left(X^{2}\right)$ and estimative errors (in $\%)$ for all the components.

\section{Characterization of grown-oxide films}


The morphology of the grown-oxide films was evaluated with a Scanning Electron Microscope equipped with a Field Emission cathode (FE/SEM), Hitachi 6500FEG. The images were taken at $7 \mathrm{kV}$ acceleration voltage.

Photoelectron spectra were recorded using a Fisons MT500 spectrometer equipped with a hemispherical electron analyser (CLAM2) and a non-monochromatic Mg Ka X-Ray source operated at $300 \mathrm{~W}$. The samples were fixed on small flat discs supported on an XYZ manipulator placed in the analysis chamber. The residual pressure in this ion-pumped analysis chamber was maintained below $10^{-9}$ torr during data acquisition. The spectra were collected at a pass energy of $20 \mathrm{eV}$, which is typical of high-resolution conditions. Spectra were analysed using CasaXPS software. The intensities were estimated by calculating the area under each peak after subtraction of the S-shaped background and fitting the experimental curve to a combination of Lorentzian and Gaussian lines of variable proportions. Although specimen charging was observed, it was possible to determine accurate binding energies (BEs) by referencing to the adventitious C1s peak at $285.0 \mathrm{eV}$. The maximum allowed variation of the binding energy was $\pm 0.2 \mathrm{eV}$ relative to the value specified for peak centre. The atomic ratios were computed from the peak intensity ratios and the reported atomic sensitivity factors [12].

\section{Localized techniques}

\section{Scanning Kelvin Probe}

Corrosion potential maps of the CoCr surfaces were acquired by means of Scanning Kelvin probe (SKP). The measurement system of SKP was developed by GS Frankel, M Stratmann et al [13]. The equipment consists of a needle that oscillates at a fixed frequency, an AC backing potential, and software analysis and control schemes. This technique can also control the distance between the tip and sample, thereby tracking the topography of the sample. The technical specifications of the SKP used are reported in [13]. SKP tests were performed at $20{ }^{\circ} \mathrm{C}$ and $99.8 \%$ relative humidity. The samples were placed in a stainless steel chamber, which was purged continuously with humidified air to maintain the relative humidity $(\mathrm{RH})$ at about $99.8 \%$, resulting in a final thin film of water on the metallic surface. After the thin layer was formed, a plane-ended cylindrical $\mathrm{Ni}-\mathrm{Cr}$ probe with a diameter of $50 \mu \mathrm{m}$ was used as needle, and was moved over the samples with three stepping motors for $\mathrm{x}, \mathrm{y}$ and $\mathrm{z}$ directions. All areas were performed stepwise and fully automated, while the sample/needle distance was maintained along the scan. 
Measurements were performed over a scanned area of $9000 \times 9000 \mu \mathrm{m}^{2}$. Before measuring, the Kelvin probe was calibrated by using a standard $\mathrm{Cu} / \mathrm{CuSO}_{4}$ solution to establish a relation between the work function and corrosion potential. SKP potentials are given relative to the potential of the Standard Hydrogen Electrode (SHE).

\section{Localized Electrochemical Impedance Spectroscopy}

This technique is based on the pioneering work of Isaac's group $[14,15]$. Fundamentals of Localized Electrochemical Impedance Spectroscopy (LEIS) measurements are detailed in Refs. $[16,17,18]$. LEIS measurements were performed with a PAR Model 370 Scanning Electrochemical Workstation that consisted of a 370 scanning control unit, a Solartron 1250 frequency response analyser, high impedance input amplifier using a differential electrometer, and a probe scanning assembly driven in the $\mathrm{x}, \mathrm{y}$, and $\mathrm{z}$ directions.

For the local electrochemical impedance measurements, a five electrode configuration was immersed in the electrolyte (PBS- $0.03 \% \mathrm{HA})$ of low conductivity $\left(\chi=15,03 \mu \mathrm{Scm}^{-1}\right.$ and $\mathrm{pH}=$ 7,8). The working electrode was the CoCr sample while a graphite bar was used as a counter electrode and $\mathrm{Ag} / \mathrm{AgCl}(\mathrm{NaCl} 3 \mathrm{M})$ electrode as a reference electrode. The configuration of the scanning probe (tip) includes two platinum probes: one of them, a platinum wire which emerges from the vertex of a conical plastic holder, and the other one, a platinum ring placed around the cone at a distance of $2 \mathrm{~mm}$ from the vertex of the cone.

The tip-surface distance was about $150 \mu \mathrm{m}$ (between 100-300 $\mu \mathrm{m}$ ). The scanning probe was moved over the surface of the working electrode.

The configuration of the scanning probe only allows the measurement of the normal component of the AC-current, i.e. the curvature of equipotential surfaces in solution is not considered. That means the radial contribution due to the equipotential curves around the centre of the electrode, is not taken into account. However, this configuration is valid only if the microelectrodes are just above the centre of the working electrode [19], as is our case, so it is important to remark that the distance between the scanning probe and the surface is not a critical parameter that influences the local impedance measured.

The local ac-current density, ilocal, resulted from the local ac potential measurement between the two platinum probes and was calculated using Ohm's law:

$$
\mathrm{i}_{\text {local }}=\Delta \varphi \mathrm{K} / \mathrm{d}
$$


where $\Delta \varphi$ is the ac-potential difference between the two probes, $\mathrm{K}$ is the electrolyte conductivity, and $d$ is the distance between the two platinum probes of the scanning probe.

The local impedance $Z_{\text {local }}$ is calculated by the relationship:

$$
Z_{\text {local }}=\Delta V_{\text {applied }} / \text { local }
$$

where $\Delta \mathrm{V}_{\text {applied }}$ is the ac-potential difference between the working electrode surface and the reference electrode in the bulk solution.

LEIS was carried out by positioning the scanning probe directly above the electrochemical region of interest. The local impedance was recorded by applying $50 \mathrm{mV}$ amplitude sinusoidal wave and a frequency range from $40 \mathrm{kHz}$ to $1 \mathrm{~Hz}$. Below this frequency the impedance data were inconsistent.

\section{RESULTS AND DISCUSSION}

\section{Overall DC techniques}

Figure 1 shows a representative anodic polarization curve for the CoCr alloy in PBS-HA. The polarization test of the $\mathrm{CoCr}$ alloy begins in the passivity zone without going through an active-passive transition because of the previous presence of the spontaneously formed oxide layer in air. Then, the current density abruptly increases at more positive potentials reaching the transpassive region.

The passive range extends from above the Ecorr (about $0.115 \mathrm{Vvs} \mathrm{Ag} / \mathrm{AgCl}$ ) to approximately $0.5 \mathrm{Vvs} \mathrm{Ag} / \mathrm{AgCl}$, increasing the current value from $10^{-9} \mathrm{~A}$ to around $10^{-6} \mathrm{~A}$, while the thickness of the oxide film increases [20]. Then, the current increases with the applied potential until a current peak of $10 \mu \mathrm{A}$ appears at approximately $0.7 \mathrm{Vvs} \mathrm{Ag} / \mathrm{AgCl}$, related to the transpassive oxidation. From this potential, the current goes up progressively with potential due to the establishment of the transpassive region until reaching $1 \mathrm{~V}$, from which the current goes down quickly as the polarization decreases. The protection potential achieved ( $0.7 \mathrm{Vvs} \mathrm{Ag} / \mathrm{AgCl})$ was higher than the previous Ecorr (about $0.115 \mathrm{Vvs} \mathrm{Ag} / \mathrm{AgCl}$ ) and a limit cathodic current is obtained at cathodic polarizations as a consequence of the stability of the grown oxide layer.

During anodic polarization, the electrochemical oxidation process results in the formation of a complex oxide layer whose composition and thickness depend on the applied potential. There is significant literature on the identification of the different oxides by spectroscopic techniques grown on $\mathrm{CoCr}$ surfaces $[9,21,22,23]$. Raman spectroscopy [24] revealed that the air-formed 
passive film on $\mathrm{CoCr}$ surfaces is composed of molybdenum (IV) oxide and $\mathrm{Cr}$ (III) oxide. After immersion in chloride aqueous solutions, molybdenum oxide is dissolved, being replaced by $\mathrm{Co}(\mathrm{OH})_{2}$, and $\mathrm{Cr}(\mathrm{III})$ oxide is partially transformed into $\mathrm{Cr}(\mathrm{OH})_{3}$. Other studies performed by XPS [9] revealed a linear ratio between the applied potential and the grown oxide thickness for polarizations higher than $0.2 \mathrm{~V}$.

Regarding the quantification of the passive oxide film, chromium is the main component of the oxide film (cationic fraction of about $90 \%$ ) at all polarizations considered (until $0.75 \mathrm{Vvs}$ $\mathrm{Ag} / \mathrm{AgCl})$. It is present primarily as $\mathrm{Cr}(\mathrm{III})$ oxide and hydroxide, although is also observed as $\mathrm{Cr}(\mathrm{VI})$ oxide from $0.5 \mathrm{Vvs} \mathrm{Ag} / \mathrm{AgCl}$ to $0.7 \mathrm{Vvs} \mathrm{Ag} / \mathrm{AgCl}$.

On the other hand, below $0.5 \mathrm{Vvs} \mathrm{Ag} / \mathrm{AgCl}$, cobalt concentrations are low (5\%) and negligible for molybdenum, increasing to $20 \%$ and $10 \%$, respectively, at higher potentials. In summary, at $0.5 \mathrm{Vvs} \mathrm{Ag/AgCl}$, chromium undergoes the beginning of the transpassive oxidation from $\mathrm{Cr}(\mathrm{III})$ to $\mathrm{Cr}(\mathrm{VI})$ and cobalt is incorporated into the oxide film mainly as $\mathrm{Co}(\mathrm{II})$ oxide; while at $0.7 \mathrm{Vvs} \mathrm{Ag} / \mathrm{AgCl}$ transpassivity of oxide film occurs, promoting a high concentration of $\mathrm{Cr}(\mathrm{VI})$ and $\mathrm{Mo}(\mathrm{VI})$ as $\mathrm{MoO}_{3}$, in the oxide film. The oxide mixture consists of $\mathrm{Cr}$ - and Mo-oxides concentrated in the outer part of the layer, whereas Co-oxide is present mainly in the inner part, closer to the oxide/metal interface. In this way, it is possible to relate the electrochemical behaviour of these passive films to their chemical compositions, due to $\mathrm{Cr}$ species playing major roles at low polarizations (passive region) and Co species seems to be involved at higher polarizations (transpassive region).

In order to assess the electrochemical properties of the oxide films that can be found on CoCr surfaces in the biological medium, different polarizations from the anodic polarization curve were chosen to be applied: 0 (at Ecorr), $0.5 \mathrm{Vvs} \mathrm{Ag} / \mathrm{AgCl}$ and $0.7 \mathrm{Vvs} \mathrm{Ag} / \mathrm{AgCl}$, i.e., $\mathrm{Cr}(\mathrm{III})$-oxide enrichment, and maximum Co(II)-oxide concentration in the grown oxide and transpassivity of the oxide film (formation of $\mathrm{Cr}(\mathrm{VI}) \mathrm{O}_{3}$ and $\mathrm{MoO}_{3}$ ), respectively. At low polarizations, the $\mathrm{Cr}(\mathrm{III})$ species play major roles in the passivation of the alloy, and at higher polarizations the $\mathrm{Cr}(\mathrm{VI})$ and $\mathrm{Mo}(\mathrm{VI})$ oxides take on these roles. It may be argued that a polarizing potential up to $0.7 \mathrm{Vvs} \mathrm{Ag} / \mathrm{AgCl}$ is unrealistically high for any biomedical application of this alloy. However, in view of the potential hazards that may arise from an enhanced metal dissolution, the increase of current recorded for 
the $\mathrm{CoCr}$ alloys at high anodic potential, over $0.5 \mathrm{Vvs} \mathrm{Ag} / \mathrm{AgCl}$, is of great interest because it seems to be the sum of different contributions, among them, water oxidation [21].

Figure 2 shows I-t plots on a logarithmic scale for $\mathrm{CoCr}$ samples polarized at $0.5 \mathrm{Vvs}$ $\mathrm{Ag} / \mathrm{AgCl}$ and $0.7 \mathrm{Vvs} \mathrm{Ag/AgCl}$ for 3600s in PBS-HA. At both potentials, the current follows a linear behaviour over time after $10 \mathrm{~s}$, however higher values of current are obtained at $0.7 \mathrm{Vvs} \mathrm{Ag/AgCl}$ corresponding to the transpassive region. Both polarizations also show similar slopes of $-0.5 \mathrm{~s}^{-1}$ which indicate that the passive oxide film growth is controlled by diffusion of ionic species through the oxide film [25]. However, while this slope remained at $0.7 \mathrm{Vvs} \mathrm{Ag} / \mathrm{AgCl}$ over the test, it was lost at $0.5 \mathrm{Vvs} \mathrm{Ag} / \mathrm{AgCl}$ after $300 \mathrm{~s}$, from which the current achieved a steady state.

At $0.5 \mathrm{Vvs} \mathrm{Ag} / \mathrm{AgCl}$, the current decreases over time, indicating that the potential increased the resistance offered by the oxide film, probably due to an increase in its thickness. This situation continues until $300 \mathrm{~s}$ when the current is stabilized until the end of the test. In the case of $0.7 \mathrm{Vvs}$ $\mathrm{Ag} / \mathrm{AgCl}$, the current remains at a high value from the initial stages, maybe due to the increase in chromium $(\mathrm{VI})$ and $\mathrm{Mo}(\mathrm{VI})$ in the passive film. All of this promotes changes in the structure and the chemical composition of the oxide film. At this point, it is important to remark that at this potential, not only the current and the ion release increase but also the concentration of hexavalent $\mathrm{Cr}$ species, a well-known carcinogen which is highly toxic in vivo environments, into the oxide film.

Figure 3 shows the Ecorr evolution versus time for the CoCr alloy before and after applying $0.5 \mathrm{Vvs} \mathrm{Ag/AgCl}$ in PBS-HA. After applying $0.5 \mathrm{Vvs} \mathrm{Ag/AgCl}$, the Ecorr reached values of around $300 \mathrm{mV}$ higher than the Ecorr for the air-formed passive film on CoCr alloy. This indicates that the potentiostatically grown oxide film is thermodynamically more stable.

Figure 4 shows potential maps of CoCr surfaces performed by SKP after applying $0.5 \mathrm{Vvs}$ $\mathrm{Ag} / \mathrm{AgCl}$ and $0.7 \mathrm{Vvs} \mathrm{Ag} / \mathrm{AgCl}$ on the CoCr alloy. Again, more favourable thermodynamic states are observed for $\mathrm{CoCr}$ surfaces after applying $0.5 \mathrm{Vvs} \mathrm{Ag} / \mathrm{AgCl}$ and $0.7 \mathrm{Vvs} \mathrm{Ag} / \mathrm{AgCl}$ compared to the air- formed passive film on CoCr alloys.

\section{Characterization of grown-oxide films}

Figure 5 shows the SEM images of CoCr samples after applying $0.5 \mathrm{Vvs} \mathrm{Ag} / \mathrm{AgCl}$ (a) and $0.7 \mathrm{Vvs} \mathrm{Ag} / \mathrm{AgCl}$ (b). The polarization at $0.5 \mathrm{Vvs} \mathrm{Ag} / \mathrm{AgCl}$ does not cause significant structural changes in the passive film (Figure 5a). However, at $0.7 \mathrm{Vvs} \mathrm{Ag} / \mathrm{AgCl}$ nanostructural changes in 
the oxide film can be seen as cylindrical nanopores of about 10-50 nm, homogeneously distributed along the surface (Figure 5b). Irregularly-shaped mesopores structures are also found in the literature as a consequence of applying a constant potential deposition [26, 27].

XPS survey spectra of surfaces of $\mathrm{CoCr}$ alloy after polarizations of $0.5 \mathrm{Vvs} \mathrm{Ag} / \mathrm{AgCl}$ and $0.7 \mathrm{Vvs} \mathrm{Ag} / \mathrm{AgCl}$ showed peaks in binding energy regions of $\mathrm{Co} 2 \mathrm{p}, \mathrm{Cr} 2 \mathrm{p}, \mathrm{Mo} 3 \mathrm{~d}, \mathrm{O} 1 \mathrm{~s}, \mathrm{C} 1 \mathrm{~s}$, N1s and P 2p. The high resolution spectrum of each element was analysed to obtain the contributions of the different chemical species formed as a consequence of the polarization at 0.5 Vvs $\mathrm{Ag} / \mathrm{AgCl}$ and $0.7 \mathrm{Vvs} \mathrm{Ag} / \mathrm{AgCl}$. As an example, Figure 6 shows the normalized XPS $\mathrm{Cr} 2 \mathrm{p}$ and Co $2 p$ and Mo $3 \mathrm{~d}$ spectra registered on polished $\mathrm{CoCr}$ alloy and after oxidation at $0.5 \mathrm{Vvs}$ $\mathrm{Ag} / \mathrm{AgCl}$ and $0.7 \mathrm{Vvs} \mathrm{Ag} / \mathrm{AgCl}$. Anodic polarization promotes a clear decrease in the metallic component in all cases and a strong increase in the oxide signal due to the formation of thicker oxide films.

After subtracting background by Shirley's method, each spectrum was decomposed into spectra originating from metallic and oxide states according to binding energy data [22, 28]. Figure 7 shows the deconvoluted spectra given for $\mathrm{Co}$ and $\mathrm{Cr}$ oxidation at $0.7 \mathrm{Vvs} \mathrm{Ag} / \mathrm{AgCl}$, after $0.5 \mathrm{Vvs} \mathrm{Ag} / \mathrm{AgCl}$ and on polished CoCr alloy, respectively. The cobalt Co 2p3/2 signal consists of 4 components assigned to: metallic cobalt at $778.0 \mathrm{eV}$; the oxide part was fitted using only one peak located in the range $780.0-781.2 \mathrm{eV}$ that consists primarily of Co2+ species, in which may be included the contribution of $\mathrm{Co} 3+$ species such as $\mathrm{CoO}, \mathrm{Co}_{2} \mathrm{O}_{3}$ and $\mathrm{Co}_{3} \mathrm{O}_{4}$; and the third and fourth components, located at $783.5 \mathrm{eV}$ and $787.0 \mathrm{eV}$ correspond to $\mathrm{Co}^{2+}$ and $\mathrm{Co}^{3+}$ shake-up satellites.

Initial signals of $\mathrm{Cr} 2 \mathrm{p} 3 / 2$ of polished $\mathrm{CoCr}$ alloy revealed three components: metallic chromium at $574.0 \mathrm{eV}$, chromium (III) oxide $\left(\mathrm{Cr}_{2} \mathrm{O}_{3}\right)$ at $576.3 \mathrm{eV}$, and chromium (III) hydroxide $\left(\mathrm{Cr}(\mathrm{OH})_{3}\right)$ at $577.2 \mathrm{eV}$. After oxidation at $0.5 \mathrm{Vvs} \mathrm{Ag} / \mathrm{AgCl}$ and $0.7 \mathrm{Vvs} \mathrm{Ag} / \mathrm{AgCl}$, a new component related to chromium ( $\mathrm{VI}$ ) appears at $578.7 \mathrm{eV}$. After oxidation at $0.5 \mathrm{Vvs} \mathrm{Ag} / \mathrm{AgCl}$ a decrease in the signal of metallic $\mathrm{Cr}$ can be observed. $\mathrm{A} \mathrm{Cr}(\mathrm{OH})_{3}$ signal becomes most important and a small peak corresponding to $\mathrm{Cr}(\mathrm{VI})$ appears. This situation is more pronounced in $\mathrm{CoCr}$ surfaces after $0.7 \mathrm{Vvs} \mathrm{Ag} / \mathrm{AgCl}$ where the metallic $\mathrm{Cr}$ and $\mathrm{Cr}_{2} \mathrm{O}_{3}$ signals have almost disappeared and the peaks corresponding to $\mathrm{Cr}(\mathrm{OH})_{3}$ and $\mathrm{Cr}(\mathrm{VI})$ clearly increase. Co $2 \mathrm{p}$ spectra show different behaviour from that described for $\mathrm{Cr} 2 \mathrm{p}$. In the polished $\mathrm{CoCr}$ alloy, the metal component is the most 
important species of this element. However, after oxidation, the metallic component diminishes and the oxide peak is predominant. The other high resolution spectra which are also deconvoluted, nor shown here, are Mo and $\mathrm{O}$. The Mo spectrum is complex because this element may be present in different oxidation states. Molybdenum presents a doublet due to the spin-orbit coupling, Mo $3 d_{5 / 2}$ and Mo $3 d_{3 / 2}$, with a binding energy difference of $3.15 \mathrm{eV}$. The signal of metallic molybdenum is observed at $227.7 \mathrm{eV}$ and due to the electrochemical oxidation, the latter peak is shifted to higher binding energies, i.e. $232.2 \mathrm{eV}$. This corresponds to the formation of Mo (VI) compounds whose contribution increased at $0.7 \mathrm{Vvs} \mathrm{Ag/AgCl}$. The oxygen O1s spectra registered three contributions at: $530.1 \mathrm{eV}$, assigned to oxygen in oxides; $531.7 \mathrm{eV}$, assigned to metalbonded hydroxide groups and $533.0 \mathrm{eV}$, related to adsorbed water.

The atomic percentage of the layers formed on $\mathrm{CoCr}$ alloy at $0.5 \mathrm{Vvs} \mathrm{Ag} / \mathrm{AgCl}$ and $0.7 \mathrm{Vvs}$ $\mathrm{Ag} / \mathrm{AgCl}$ deduced from XPS spectra are given in Table 2. All surfaces contain a high level of carbon, due to exposure to air. There is also an enrichment in oxygen and chromium, due to the prevalent formation of a chromium oxide layer. The cobalt content clearly decreased with the polarization, as can be seen in the decrease of the $\mathrm{Co} / \mathrm{Cr}$ ratio. Therefore, it can be said that, after polarization, preferential dissolution of cobalt occurred whereas chromium is concentrated in the surface oxide film. Molybdenum content is very low $(\leq 1 \%)$. Other components included in the oxide layers, after polarization, are $\mathrm{N}$ and $\mathrm{P}$ coming from the electrolyte.

From the XPS spectra it can be concluded that the passive film grown at $0.5 \mathrm{Vvs} \mathrm{Ag} / \mathrm{AgCl}$ (into the passive region of the anodic polarization curve) consists predominantly of $\mathrm{Cr}_{2} \mathrm{O}_{3}$ and $\mathrm{Cr}(\mathrm{OH})_{3}$. However, the oxidation at $0.7 \mathrm{Vvs} \mathrm{Ag} / \mathrm{AgCl}$ causes the appearance of $\mathrm{Cr}(\mathrm{VI})$ and also $\mathrm{Mo}(\mathrm{VI})$ species into the passive film. These results are in agreement with those described in the literature [22, 25].

\section{Overall $A C$ measurements}

Figure 8 shows the overall impedance data for $\mathrm{CoCr}$ samples at the Ecorr and after previous polarizations at $0.5 \mathrm{Vvs} \mathrm{Ag} / \mathrm{AgCl}$ and $0.7 \mathrm{Vvs} \mathrm{Ag} / \mathrm{AgCl}$. The Nyquist diagrams (Figure 8a) are characterized by capacitive arcs in all frequency ranges whose magnitude depends on the characteristics of the oxide film grown on the CoCr surface. In fact, the diameter of the capacitive arcs decreased as the polarization previously applied was higher, i.e., the higher the polarization, 
the smaller its magnitude. The same was also observed from the Bode diagram of impedance modulus (Figure 8b). However, phase angle from the Bode diagram (Figure 8c) is a much more sensitive indicator that allows better monitoring. At the low frequency range, the phase angle values clearly increased with polarization: - 80 (at Ecorr), - 60 (at $0.5 \mathrm{Vvs} \mathrm{Ag} / \mathrm{AgCl}$ ), and $0^{\circ}$ (at $0.7 \mathrm{Vvs} \mathrm{Ag} / \mathrm{AgCl}$ ). After polarization at $0.7 \mathrm{Vvs} \mathrm{Ag} / \mathrm{AgCl}$, the $\mathrm{CoCr}$ alloy showed the highest phase angle and the lowest impedance modulus at low frequencies, together with a depressed semicircle with the lowest diameter in the whole frequency range. Therefore, these results indicate that the electrochemical modification of the oxide films promotes the formation of defects or less resistant films.

The growth of oxide films by potentiostatic pulses modifies the chemical composition, thickness and structure of the oxide film generated with respect to the passive film formed by air contact. These modifications can provoke more surface disorder (heterogeneities at the atomic scale), geometric irregularities, such as roughness, and a variation of the oxide composition. This leads to the time constant dispersion that is attributed to a dispersion of the capacity or to a change of the capacity with frequency [29]. In such cases, a constant phase element (CPE) is often used in modelling the alternating current response instead of a pure capacitor.

The CPE behaviour of each surface can be quantified by plotting the imaginary part of the impedance as a function of frequency on logarithmic scale. The slope of the straight line gives us the exponent alpha, i.e., the variation from the ideal capacitor $(\alpha=1)$ to CPE behaviour $(\alpha<1)$. Figure 9a shows the imaginary impedance versus frequency on logarithmic scale obtained at Ecorr, and after $0.5 \mathrm{Vvs} \mathrm{Ag} / \mathrm{AgCl}$ and $0.7 \mathrm{Vvs} \mathrm{Ag} / \mathrm{AgCl}$. This plot allows the calculation of $\alpha$, associated with CPE, to be obtained directly without regression of the equivalent circuit. The slopes are constant in the whole frequency range, except for the $\mathrm{CoCr}$ surface after applying 0.7 Vvs $\mathrm{Ag} / \mathrm{AgCl}$, in which the straight line is lost at frequencies below $1 \mathrm{~Hz}$.

Slopes of $-0.93,-0.85$ and -0.72 corresponding to $\alpha$ exponent are obtained for $\mathrm{CoCr}$ samples at the Ecorr, $0.5 \mathrm{Vvs} \mathrm{Ag} / \mathrm{AgCl}$ and $0.7 \mathrm{Vvs} \mathrm{Ag} / \mathrm{AgCl}$, respectively. These slopes, higher than -1 , allow us to verify the CPE behaviour of the CoCr surfaces, especially for oxide films grown on CoCr surfaces after applying $0.5 \mathrm{Vvs} \mathrm{Ag} / \mathrm{AgCl}$ and $0.7 \mathrm{Vvs} \mathrm{Ag} / \mathrm{AgCl}$.

The different structure and chemical composition of the respective oxide films formed at 0.5 Vvs $\mathrm{Ag} / \mathrm{AgCl}$ and $0.7 \mathrm{Vvs} \mathrm{Ag} / \mathrm{AgCl}$ induces changes in the electrochemical response of the 
surfaces. The potential difference applied through a film with an Ohmic behaviour of inhomogeneous thickness generates an electric field that is a function of the length along the surface under consideration. The impedance response will be influenced by the properties of the grown-film on the surface in terms of distribution of the time constants. The frequency dispersion can be particularly evident by plotting, on logarithmic scale, the imaginary part versus the real part of the impedance that allows us to distinguish between the types of oxide grown on the surface. Figure 9b shows the impedance plots for CoCr samples with the air-grown passive film and those grown at $0.5 \mathrm{Vvs} \mathrm{Ag} / \mathrm{AgCl}$ and $0.7 \mathrm{Vvs} \mathrm{Ag} / \mathrm{AgCl}$. In all cases, the shape of the impedance curves agree closely with an Ohmic behaviour with graded thickness [30], especially for oxide films grown at $0.7 \mathrm{Vvs} \mathrm{Ag} / \mathrm{AgCl}$, which is responsible for the most evident time constant distribution and so the presence of CPE.

In the view of these results, Table 3 shows the fitting of the experimental impedance data of the grown-oxide on $\mathrm{CoCr}$ and the Randles equivalent circuit used, where Rs is the solution resistance, CPE is the constant phase element, $n$ is the exponent associated with CPE, $\mathrm{R}_{\text {oxide film }}$ is the oxide film resistance and $\mathrm{X}^{2}$ is the chi-square value. It can be seen that the resistance of oxide films grown on $\mathrm{CoCr}$ samples decreases with increasing the potential applied. This behaviour is followed by the increase in the CPE values and the decrease of $n$ exponent as polarization increases, denoting more defective oxide films with higher frequency dispersion.

It is also interesting to note the good agreement between a exponents, calculated from the experimental impedance data (Figure 9a), and $\mathrm{n}$ exponents obtained from fitting by using the equivalent circuit (Table 3).

The protective properties of the oxide film generated at $0.7 \mathrm{Vvs} \mathrm{Ag} / \mathrm{AgCl}$ are the poorest of all surface conditions. This is supported by the lowest value of the exponents, $\alpha$ and $n$, showing a noticeable capacitance distribution on this surface, not only by the graded Ohmic behaviour of the oxide films but also by the surface inhomogeneity (associated with nanopores structure seen by SEM in Figure 5b), created by the transpassive oxidations from $\mathrm{Cr}(\mathrm{III})$ to $\mathrm{Cr}(\mathrm{VI})$ and $\mathrm{Mo}(\mathrm{IV})$ to $\mathrm{Mo}(\mathrm{VI})$ species in the oxide film.

\subsubsection{Local AC measurements}

The CPE behaviour can follow two types of distribution of time constants: a two-dimensional (2D) distribution from the current and/or potential distributions along the surface, and a three- 
dimensional (3D) distribution from effects in the normal dimension to the surface such as roughness or varying the chemical composition through the thickness of the oxide film. For both 2D and 3D distributions, the overall impedance results from an integration of local impedances along the electrode surface. Considering this, some authors have noted the convenience of using the local electrochemical impedance spectroscopy in order to distinguish between $2 \mathrm{D}$ and $3 \mathrm{D}$ distributions [23]. In the case of 2D distributions, local impedance would serve to measure a single element that does not have CPE behaviour, unlike the result obtained from overall electrochemical impedance spectroscopy. On the other hand, in the case of 3D distributions, the local element will reveal CPE behaviour with the same exponent as seen in the overall impedance measurement.

Figure 10 shows local impedance diagrams in Nyquist format for CoCr samples at the Ecorr and after previous polarizations at $0.5 \mathrm{Vvs} \mathrm{Ag} / \mathrm{AgCl}$ and $0.7 \mathrm{Vvs} \mathrm{Ag} / \mathrm{AgCl}$. A well-defined semicircle is observed at high frequencies, in contrast with the EIS overall results (Figure 8). This could mean that the local impedance responses are sensitive for detecting the presence of the oxide film grown at $0.5 \mathrm{Vvs} \mathrm{Ag} / \mathrm{AgCl}$ and $0.7 \mathrm{Vvs} \mathrm{Ag} / \mathrm{AgCl}$. In fact, the higher polarization the better semicircle definition, indicating a higher resistive behaviour for the polarized $\mathrm{CoCr}$ samples against capacitive character of the oxide film created in air.

The imaginary part of the impedance as a function of frequency on logarithmic scale is shown in Figure 11 in order to analyse the CPE behaviour of the different CoCr samples. The diagrams are characterized by straight lines with two different slopes: one at the high frequencies related to the oxide film and another at low frequencies. The a value estimated from the local impedance measurements at the high frequency range of the passive film on $\mathrm{CoCr}$ samples at the Ecorr, remains at the same value as those obtained from overall impedance. However, the $\alpha$ values estimated from the local impedance measurements of the oxide-grown films of $\mathrm{CoCr}$ samples applying $0.5 \mathrm{Vvs} \mathrm{Ag} / \mathrm{AgCl}$ and $0.7 \mathrm{Vvs} \mathrm{Ag} / \mathrm{AgCl}$ approaches -0.5. This means that the oxide grown films at $0.5 \mathrm{Vvs} \mathrm{Ag} / \mathrm{AgCl}$ and $0.7 \mathrm{Vvs} \mathrm{Ag} / \mathrm{AgCl}$ follow a three-dimensional (3D) distribution, probably due, as mentioned above, to the surface inhomogeneities and resistive properties generated by the growth of the oxide films. 
Summarizing, local impedance techniques are useful tools for revealing the different electrochemical properties of the oxide films grown on metallic samples that can appear in vivo conditions.

\section{CONCLUSIONS}

The local techniques are able to supply deep mechanistic information about the electrochemical properties of oxide films that can be formed under biological environments on the metallic implants.

Oxide-grown films by potentiostatic pulses are thermodynamically more stable than the airgenerated passive film on CoCr alloys. However, the kinetics behaviour shows the opposite trend, i.e., the higher polarization the worse anticorrosive properties. Oxide grown films at $0.5 \mathrm{Vvs}$ $\mathrm{Ag} / \mathrm{AgCl}$ and $0.7 \mathrm{Vvs} \mathrm{Ag} / \mathrm{AgCl}$ follow a three-dimensional (3D) distribution probably due to the surface inhomogeneities and resistive properties generated by the growth of the oxide films. At $0.7 \mathrm{Vvs} \mathrm{Ag/AgCl}$, the oxide film generated has the poorest anticorrosive properties of all surface conditions. This behaviour is accompanied by the low value of the $n$, showing the capacitance distribution on this surface, not only due to the graded Ohmic behaviour of the oxide film but also to the surface inhomogeneity.

\section{ACKNOWLEDGEMENTS}

This work was supported by the Spanish National government [MINECO-MAT2011-29152C02-01].

\section{REFERENCES}

[1] C. Valero Vidal, A. Igual Muñoz, Electrochemical characterization of biomedical alloys for surgical implants in simulated body fluids, Corros. Sci. 50 (2008) 1954-1961.

[2] Y. Yan, A. Neville, D. Dowson, Tribocorrosion properties of cobalt-based medical implant alloys in simulated biological environments, Wear 263 (2007) 1105-1111.

[3] A. I. Muñoz, S. Mischler, Interactive effects of albumin and phosphate ions on the corrosion of CoCr implant alloy, J. Electrochem. Soc. 154 (2007) C562-C570.

[4] R. Sonntag, J. Reinders, J. P. Kretzer, What's next? Alternative materials for articulation in total joint replacement, Acta Biomater. 8 (2012) 2434-2441.

[5] M. Haeri, J. L. Gilbert, Study of cellular dynamics on polarized $\mathrm{CoCr}$ alloy using time-lapse live-cell imaging, Acta Biomater. 9 (2013) 9220-9228.

[6] A Ouerd, C Alemany-Dumont, B Normand, S Szunerits, Reactivity of CoCr alloy in physiological medium: Electrochemical characterization of the metal/protein interface, Electrochimica Acta 53 (2008) 4461-4469. 
[7] CD McCaig, AM. Rajnicek, B. Song, M Zhao, Controlling Cell Behavior Electrically: Current Views and Future Potential, Physiol Rev 85 (1985) 943-978.

[8] AWE Hodgson, S. Kurz, S. Virtanen, V. Fervel, C-OA Olsson, S Mischler, Passive and transpassive behavior of $\mathrm{CoCr}$ in simulated biological solutions, Electrochim. Acta 49 (2004) 2167-2178.

[9] R.A. Gittens, R. Olivares-Navarrete, R. Tannenbaum, B.D. Boyan, Z. Schwartz, Electrical implications of corrosion for osseointegration of titanium implants, J Dent Res. 90 (2011) 13891397.

[10] A.Y. Hui, W.J. McCarty, K. Masuda, G.S. Firestein, R.L. Sah, A systems biology approach to synovial joint lubrication in health, injury, and disease, Wiley Interdiscip Rev Syst Biol Med. 4 (2012) 15-37.

[11] J. Black, in Biological Performance of Materials: Fundamentals of Biocompatibility, Marcel Decker, New York, USA, 1992. p. 38-60.

[12] C.D Wagner, L.E Davis, M.V Zeller, J.A Taylor, R.M Raymond, L.H. Gale, Empirical atomic sensitivity factors for quantitative analysis by electron spectroscopy for chemical analysis. Surf. Interface Anal. 3 (1981) 211-225.

[13] G.S. Frankel, M. Stratmann, M. Rohwerder, A. Michalik, B. Maier, J. Dora, M. Wicinski, Potential control under thin aqueous layers using a Kelvin Probe, Corros. Sci. 49 (2007) 20212036.

[14] R.S. Lillard, P.J. Moran, H.S. Isaacs, A novel method for generating quantitative local electrochemical impedance spectroscopy, J. Electrochem. Soc. 139 (1992) 1007-1012.

[15] F. Zou, D. Thierry, H.S. Isaacs, A high resolution probe for localized electrochemical impedance spectroscopy measurements, J. Electrochem. Soc. 144 (1997) 1957-1965.

[16] C. Blanc, M.E. Orazem, N. Pebere, B. Tribollet, V. Vivier, S. Wu, The origin of the complex character of the Ohmic impedance, Electrochim. Acta 55 (2010) 6313-6321.

[17] I. Frateur, V.M.W. Huang, M.E. Orazem, B. Tribollet, V. Vivier, Experimental issues associated with measurement of local electrochemical impedance, J. Electrochem. Soc.154 (2007) C719-C727.

[18] V.M.W. Huang, S.L. Wu, M.E. Orazem, N. Pebere, B. Tribollet, V. Vivier, Local electrochemical impedance spectroscopy: A review and some recent developments, Electrochim. Acta 56 (2011) 8048-8057.

[19] JV Ferrari, HG De Melo, M Keddam, ME Orazem, N Pebere, B. Tribollet, V. Vivier, Influence of normal and radial contributions of local current density on local electrochemical impedance spectroscopy. Electrochim. Acta, 60 (2012) 244-252.

[20] I. Milosev, CoCr alloy for biomedical applications, in: Biomedical applications. Modern Aspects of Electrochemistry, S. Djokic (Ed.). Springer Science+Business Media, New York 2012.

[21] E. Bettini, C. Leygraf, J. Pan, Nature of Current Increase for a CoCrMo Alloy: "transpassive" Dissolution vs. Water Oxidation. Int. J. Electrochem. Sci., 8 (2013) 11791 11804.

[22] I. Milosev, The effect of biomolecules on the behaviour of CoCrMo alloy in various simulated physiological solutions. Electrochim. Acta 78 (2012) 259- 273.

[23] I. Milosev, J. Hmeljak, A. Cor, Hyaluronic acid stimulates the formation of calcium phosphate on CoCrMo alloy in simulated physiological solution. J Mater Sci: Mater Med 24 (2013) 555-571. 
[24] Y-S Li, K Wang, P. He, B X Huang, P. Kovacs. Surface-enhanced Raman Spectroelectrochemical studies of corrosion films on implant $\mathrm{CoCr}$ alloy in biosimulating solution. J. Raman Spectrosc. 30 (1999) 97-103.

[25] S. Maximovitch. Influence of formation conditions on impedance properties of nickel passive layers formed in $1 \mathrm{M} \mathrm{KOH}$, Electrochim. Acta. 41 (1996) 2761-2771.

[26] C Li, H Wang,Y Yamauchi, Electrochemical Deposition of Mesoporous Pt-Au Alloy Films in Aqueous Surfactant Solutions: Towards a Highly Sensitive Amperometric Glucose Sensor, Chem Euro J, 19, (2013) 2242-2246.

[27] K-C Kao, C-H Lin, T-Y Chen, Y-H Liu, C-Y Mou, A General Method for Growing Large Area Mesoporous Silica Thin Films on Flat Substrates with Perpendicular Nanochannels, J. Am. Chem. Soc., 137 (2015) 11558-11561.

[28] C.D Wagner, W.M Riggs, L.E Davies, J.F. Moulder, G.E. Muilenberg, Handbook of X-ray Photoelectron Spectroscopy, Perkin Elmer, Eden Prairie, MN, 1979.

[29] J-B. Jorcin, M.E. Orazem, N. Pebere, B. Tribollet, CPE analysis by local electrochemical impedance spectroscopy, Electrochim. Acta 51 (2006) 1473-1479.

[30] S. Cattarin, M. Musiani, B. Tribollet, V. Vivier, Impedance of passive films with graded thickness: Influence of the electrode and cell geometry, Electrochim. Acta 54 (2009) 6963-6970. 


\section{HIGHLIGTHS}

- High potentials in an oxide film on CoCr surfaces induce change in CPE distribution

- CPE distribution of CoCr surfaces after applying high potentials agrees with 3D model

- Oxide films grown on CoCr follow a closely Ohmic behaviour with graded thickness

- Potentials at $0.7 \mathrm{Vvs} \mathrm{Ag} / \mathrm{AgCl}$ causes nanostructural change in oxide surfaces

- Nanopores of 10-50 nm diameter are formed along surface at $0.7 \mathrm{Vvs} \mathrm{Ag} / \mathrm{AgCl}$ 


\section{TABLES}

\begin{tabular}{cccccccccccccc}
\hline & C & Co & Cr & Mo & Ni & S & P & Al & W & Mn & Fe & Si & N \\
\hline HC & 0.22 & 62 & 29.4 & 6.4 & 0.1 & 0.004 & 0.001 & 0.01 & 0.03 & 0.7 & 0.16 & 0.7 & 0.16 \\
\hline
\end{tabular}

Table 1. Chemical composition of high carbon CoCr alloy.

\begin{tabular}{|c|c|c|c|c|c|c|c|}
\hline & $\begin{array}{c}0 \\
\text { (at\%) }\end{array}$ & $\begin{array}{c}\text { C } \\
\text { (at\%) }\end{array}$ & $\begin{array}{c}\text { Co } \\
\text { (at\%) }\end{array}$ & $\begin{array}{c}\mathrm{Cr} \\
\text { (at\%) }\end{array}$ & $\begin{array}{c}\text { Mo } \\
\text { (at\%) }\end{array}$ & $\begin{array}{c}\mathbf{N} \\
\text { (at\%) }\end{array}$ & $\begin{array}{c}\mathbf{P} \\
\text { (at\%) }\end{array}$ \\
\hline polished & 28.5 & 57.3 & 5.8 & 7.3 & 1.1 & 0.0 & 0.0 \\
\hline $0.5 \mathrm{Vvs} \mathrm{Ag} / \mathrm{AgCl}$ & 40.6 & 42.6 & 3.8 & 7.9 & 0.9 & 2.7 & 1.5 \\
\hline $0.7 \mathrm{Vvs} \mathrm{Ag/AgCl}$ & 44.6 & 38.5 & 2.8 & 7.6 & 0.6 & 3.4 & 2.6 \\
\hline
\end{tabular}

Table 2. Atomic percentage (at.\%) from high resolution XPS spectra of each element present in the layers formed on $\mathrm{CoCr}$ alloy in polished, and after $0.5 \mathrm{Vvs} \mathrm{Ag} / \mathrm{AgCl}$ and $0.7 \mathrm{Vvs} \mathrm{Ag} / \mathrm{AgCl}$ in PBS-HA. 


\begin{tabular}{|c|c|c|c|c|c|}
\hline & Rs $(\Omega)$ & $\begin{array}{c}\mathrm{CPE}_{\text {oxide }} \\
\times 10^{-6}\left(\mathrm{~S} \mathrm{~s}^{\mathrm{n}}\right)\end{array}$ & $\mathbf{n}$ & $\begin{array}{l}R_{\text {oxide film }} \\
\times 10^{3}(\Omega)\end{array}$ & $\begin{array}{c}X^{2} \\
\times 10^{-3}\end{array}$ \\
\hline Ecorr & 105.3 & 10.57 & 0.935 & 22370 & 1.43 \\
\hline $0.5 \mathrm{Vvs} \mathrm{Ag} / \mathrm{AgCl}$ & 162.4 & 14.42 & 0.858 & 226.7 & 1.41 \\
\hline $0.7 \mathrm{Vvs} \mathrm{Ag} / \mathrm{AgCl}$ & 140.2 & 37.62 & 0.757 & 7.98 & 3.21 \\
\hline
\end{tabular}

$\mathrm{CPE}\left(\mathrm{Y}_{\mathbf{0}}, \mathbf{n}\right)$

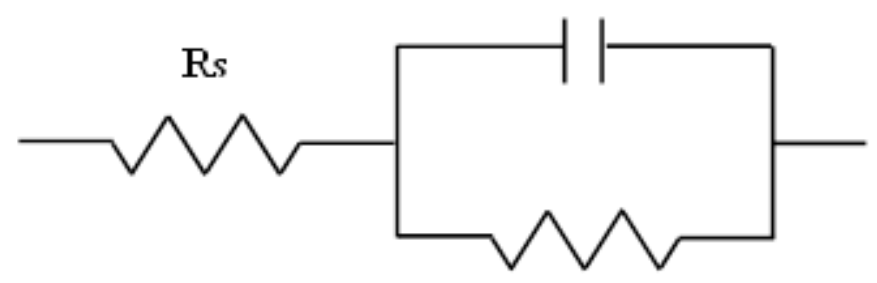

$R_{\text {oxide fllm }}$

Table 3. Fitting and Randles equivalent circuit of experimental overall impedance data for $\mathrm{CoCr}$ samples on polished (Ecorr) and after $0.5 \mathrm{Vvs} \mathrm{Ag} / \mathrm{AgCl}$ and $0.7 \mathrm{Vvs} \mathrm{Ag} / \mathrm{AgCl}$ in PBS-HA. (Rssolution resistance; CPE- Phase Constant Element; $n$-exponent; Roxide film-oxide film Resistance; $\mathrm{X}^{2}$ - chi-square value). 


\section{FIGURE CAPTIONS}

Figure 1. Anodic polarization curve for the CoCr alloy in PBS-HA at $10 \mathrm{mV} / \mathrm{min}$ scanning rate.

Figure 2. I-t plots on logarithmic scale for the $\mathrm{CoCr}$ samples after polarization at $0.5 \mathrm{Vvs} \mathrm{Ag} / \mathrm{AgCl}$ ( - ) and $0.7 \mathrm{Vvs} \mathrm{Ag} / \mathrm{AgCl}\left(^{--^{-}}\right.$) for 3600s in PBS-HA.

Figure 3. $E_{\text {corr }}$ evolution versus time for the $\mathrm{CoCr}$ alloy before, Ecorr, ( - - ) and after polarization at $0.5 \mathrm{Vvs} \mathrm{Ag} / \mathrm{AgCl}(-\bullet)$ in PBS-HA.

Figure 4. Topographical and potential maps $\left(9000 \times 9000 \mathrm{~mm}^{2}\right)$ by scanning kelvin probe for the CoCr samples after polarization at $0.5 \mathrm{Vvs} \mathrm{Ag} / \mathrm{AgCl}(\mathrm{a})$, and $0.7 \mathrm{Vvs} \mathrm{Ag} / \mathrm{AgCl}$ (b)

Figure 5. SE images of the CoCr surfaces after polarization at $0.5 \mathrm{Vvs} \mathrm{Ag} / \mathrm{AgCl}$ (a) and $0.7 \mathrm{Vvs}$ $\mathrm{Ag} / \mathrm{AgCl}(\mathrm{b})$.

Figure 6. Normalized XPS Co $2 p, \mathrm{Cr} 2 \mathrm{p}$ and Mo $3 \mathrm{~d}$ spectra obtained after polarization at $0.7 \mathrm{Vvs}$ $\mathrm{Ag} / \mathrm{AgCl}$ and $0.5 \mathrm{Vvs} \mathrm{Ag} / \mathrm{AgCl}$ and on the polished $\mathrm{CoCr}$ alloy.

Figure 7: Deconvoluted XPS Co $2 p_{3 / 2}$ and $\mathrm{Cr} 2 \mathrm{p}_{3 / 2}$ spectra recorded at the oxide layer formed after polarization at $0.7 \mathrm{Vvs} \mathrm{Ag} / \mathrm{AgCl}$ and $0.5 \mathrm{Vvs} \mathrm{Ag/AgCl}$ and on the polished $\mathrm{CoCr}$ alloy.

Figure 8. Overall impedance data for the CoCr samples in PBS-HA at Ecorr ( - - ) and after polarization at $0.5 \mathrm{Vvs} \mathrm{Ag} / \mathrm{AgCl}(--)$ ) and $0.7 \mathrm{Vvs} \mathrm{Ag} / \mathrm{AgCl}$ (-^-) a) Nyquist diagram; b) impedance modulus Bode plot; c) phase angle Bode plot.

Figure 9. Impedance diagrams of the CoCr alloys in PBS-HA at Ecorr ( - - ) and after polarization at $0.5 \mathrm{Vvs} \mathrm{Ag/AgCl} \mathrm{(--)} \mathrm{and} 0.7 \mathrm{Vvs} \mathrm{Ag} / \mathrm{AgCl}(-\boldsymbol{-})$ ): a) Imaginary impedance versus frequency; $b$ ) imaginary impedance versus real impedance, on logarithmic coordinates.

Figure 10. Nyquist plot of the local electrochemical impedance response of the CoCr alloy in PBS$\mathrm{HA}$ at Ecorr (- - ) and after polarization at $0.5 \mathrm{Vvs} \mathrm{Ag} / \mathrm{AgCl}(--)$ ) and $0.7 \mathrm{Vvs} \mathrm{Ag} / \mathrm{AgCl}$ ( -스).

Figure 11. Local imaginary impedance versus frequency, on logarithmic coordinates, of the $\mathrm{CoCr}$ alloy in PBS-HA at Ecorr ( - - ) and after polarization at $0.5 \mathrm{Vvs} \mathrm{Ag} / \mathrm{AgCl}$ ( - - ) and $0.7 \mathrm{Vvs}$ $\mathrm{Ag} / \mathrm{AgCl}(\boldsymbol{-}-\boldsymbol{C})$. 


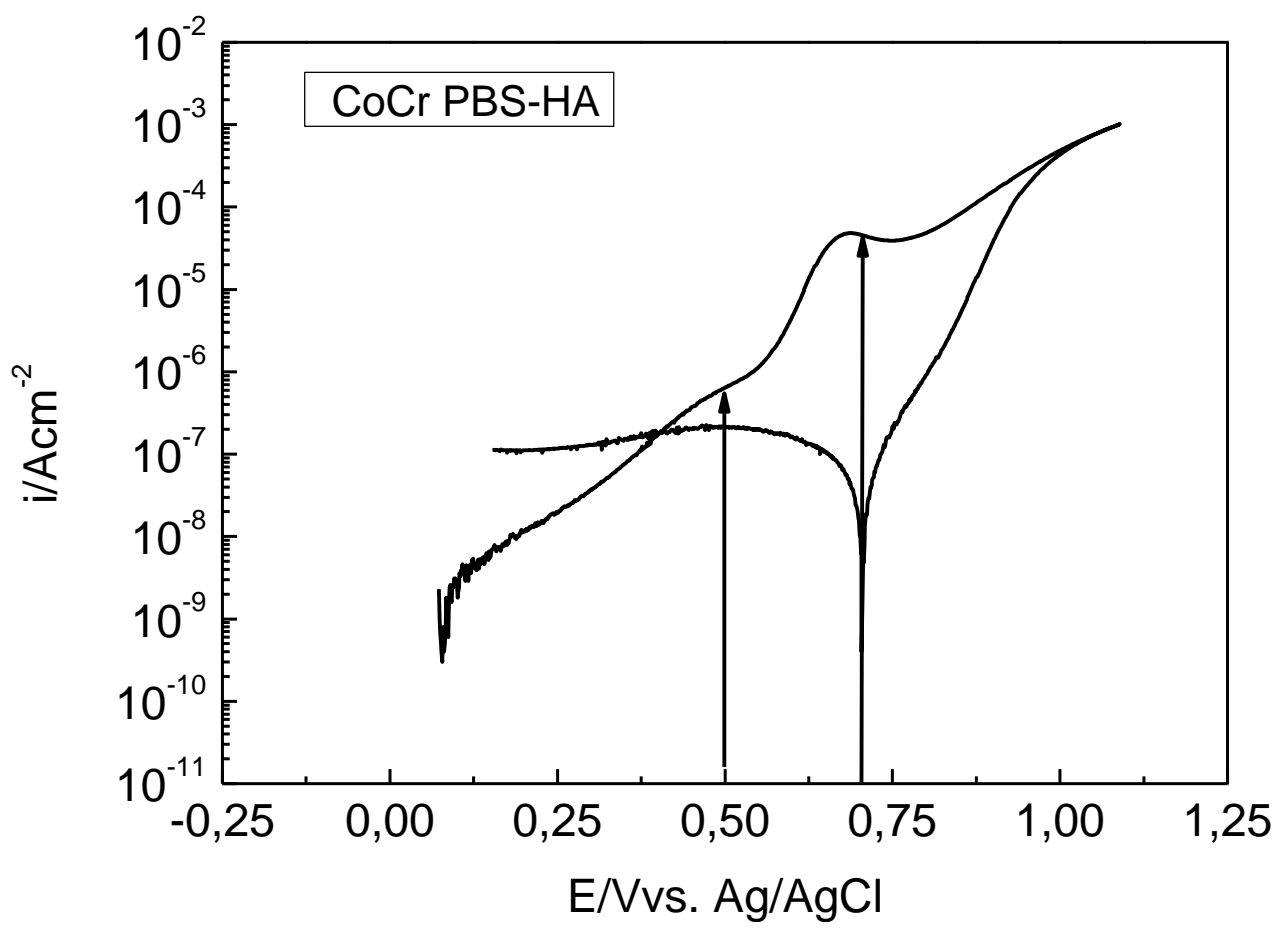

Figure 1 


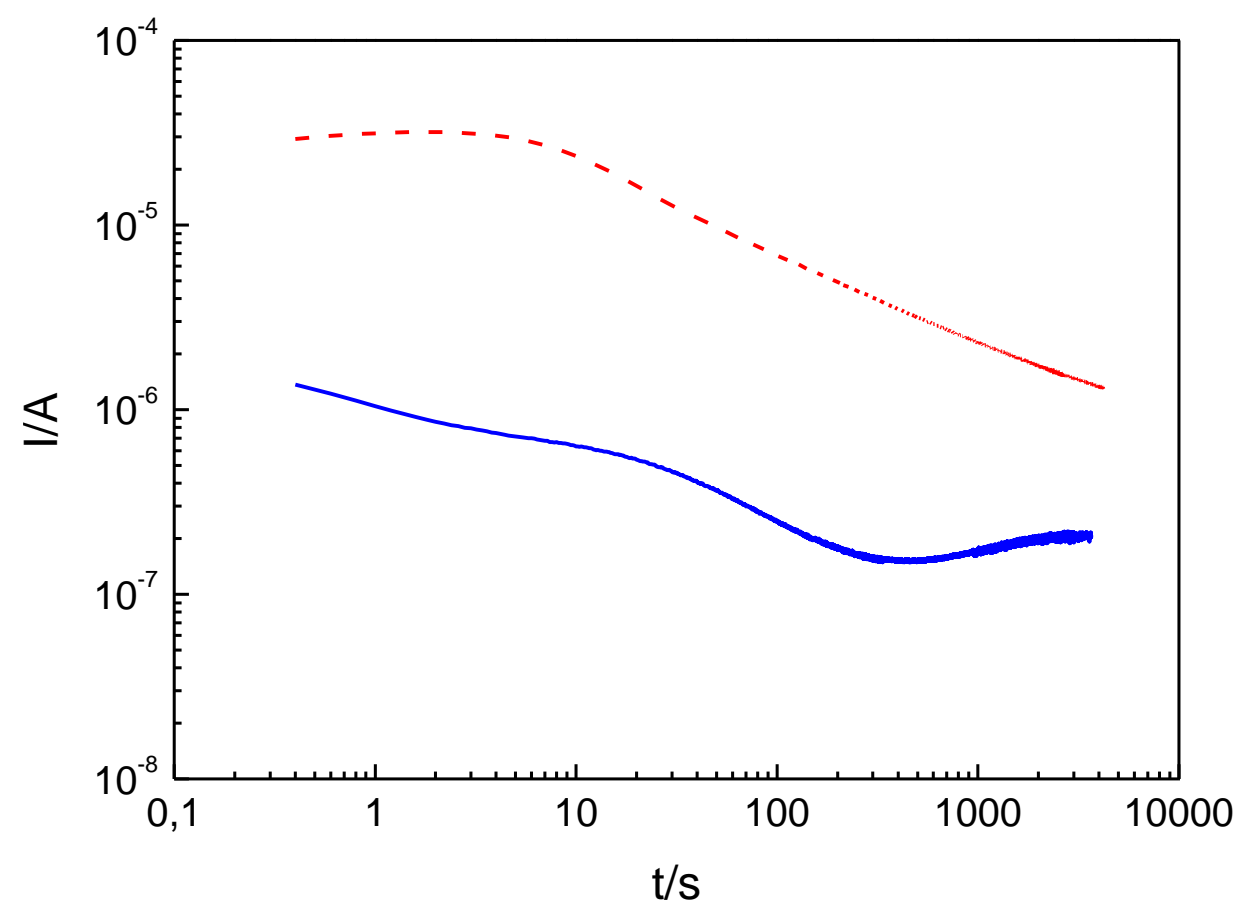

Figure 2 


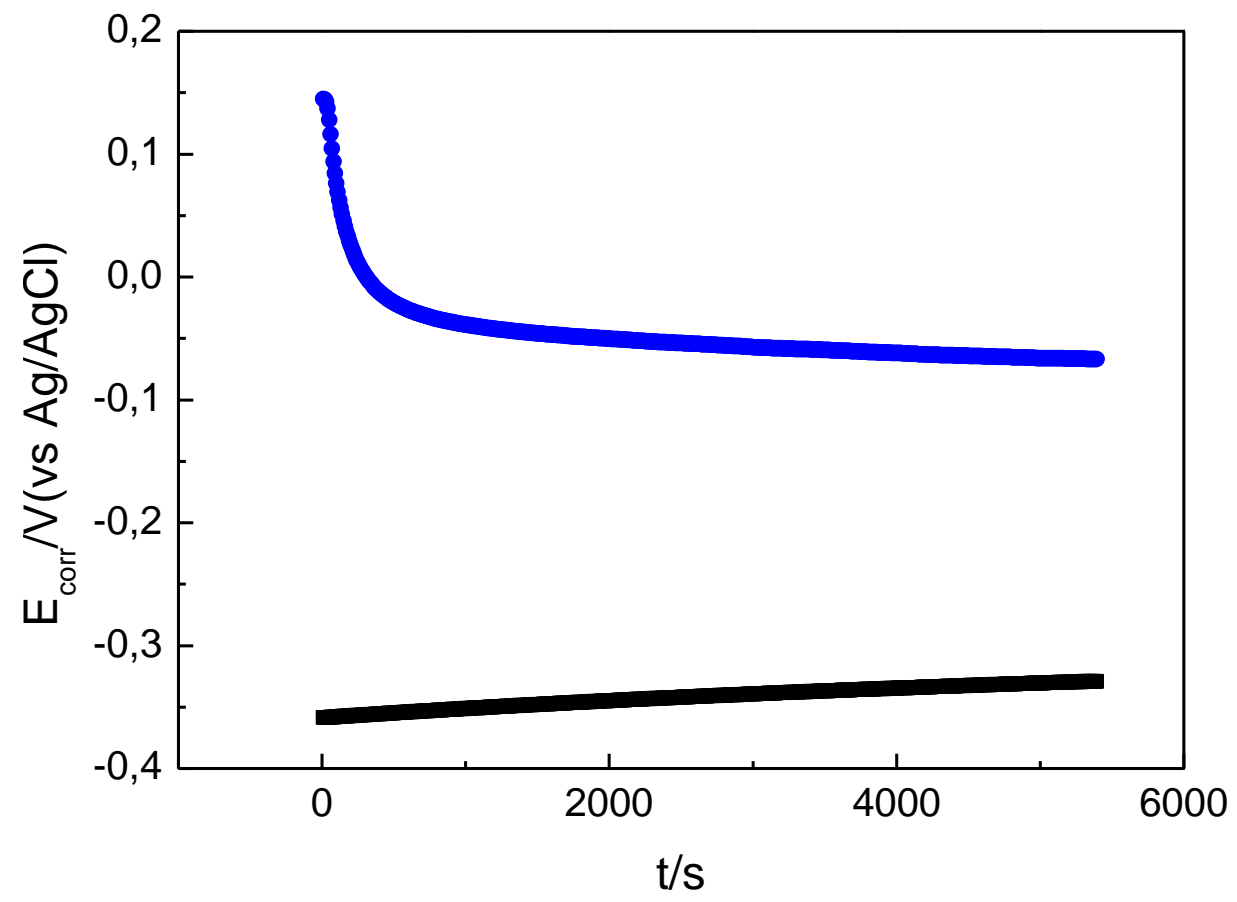

Figure 3 


\section{$0.5 \mathrm{Vvs} \mathrm{Ag/AgCl}$}
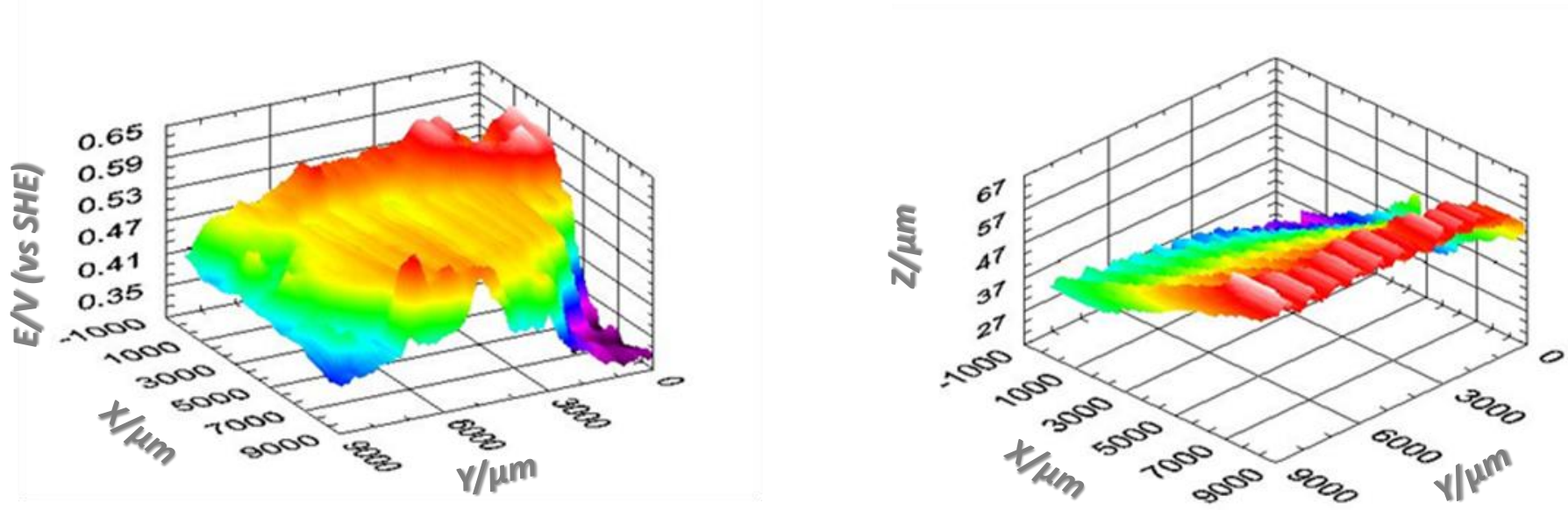

a)

\section{$0.7 \mathrm{Vvs} \mathrm{Ag} / \mathrm{AgCl}$}
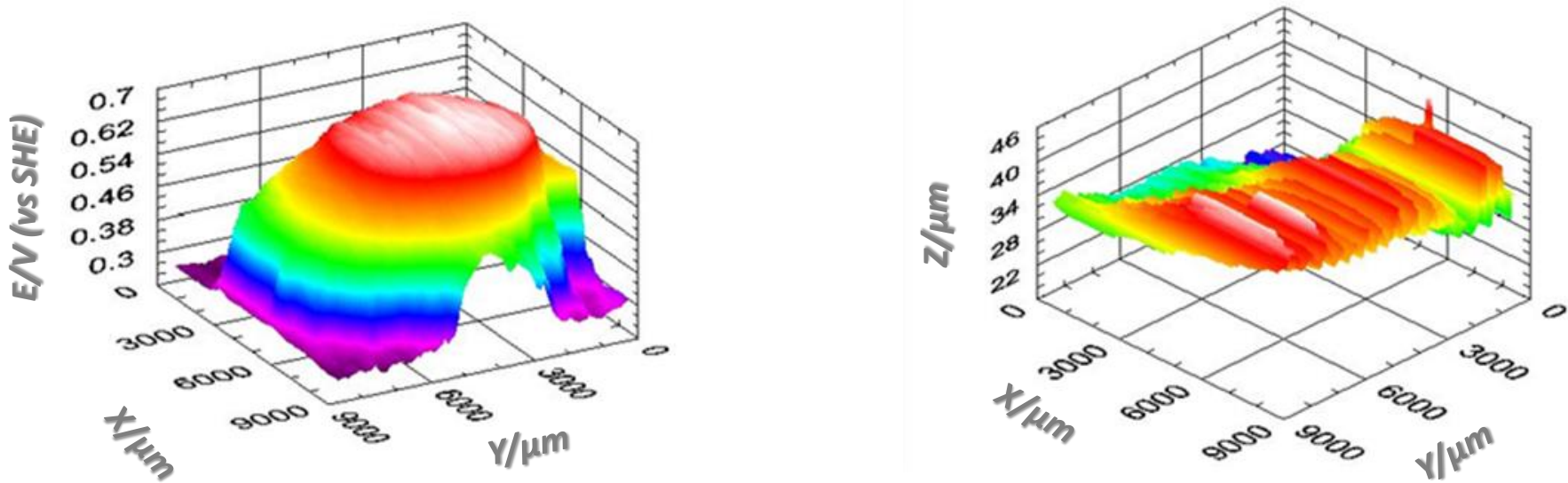

b)

Figure 4 


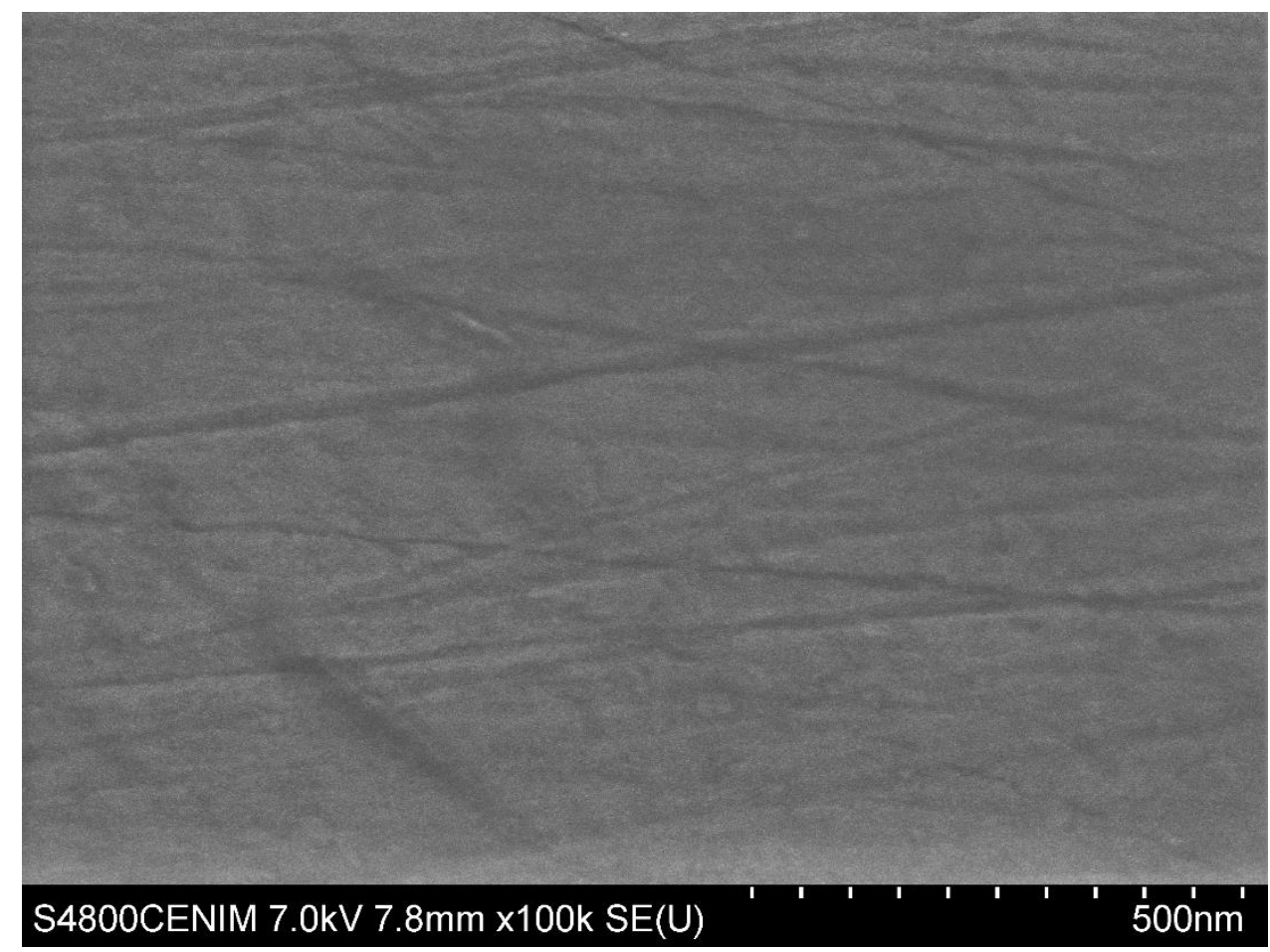

a)

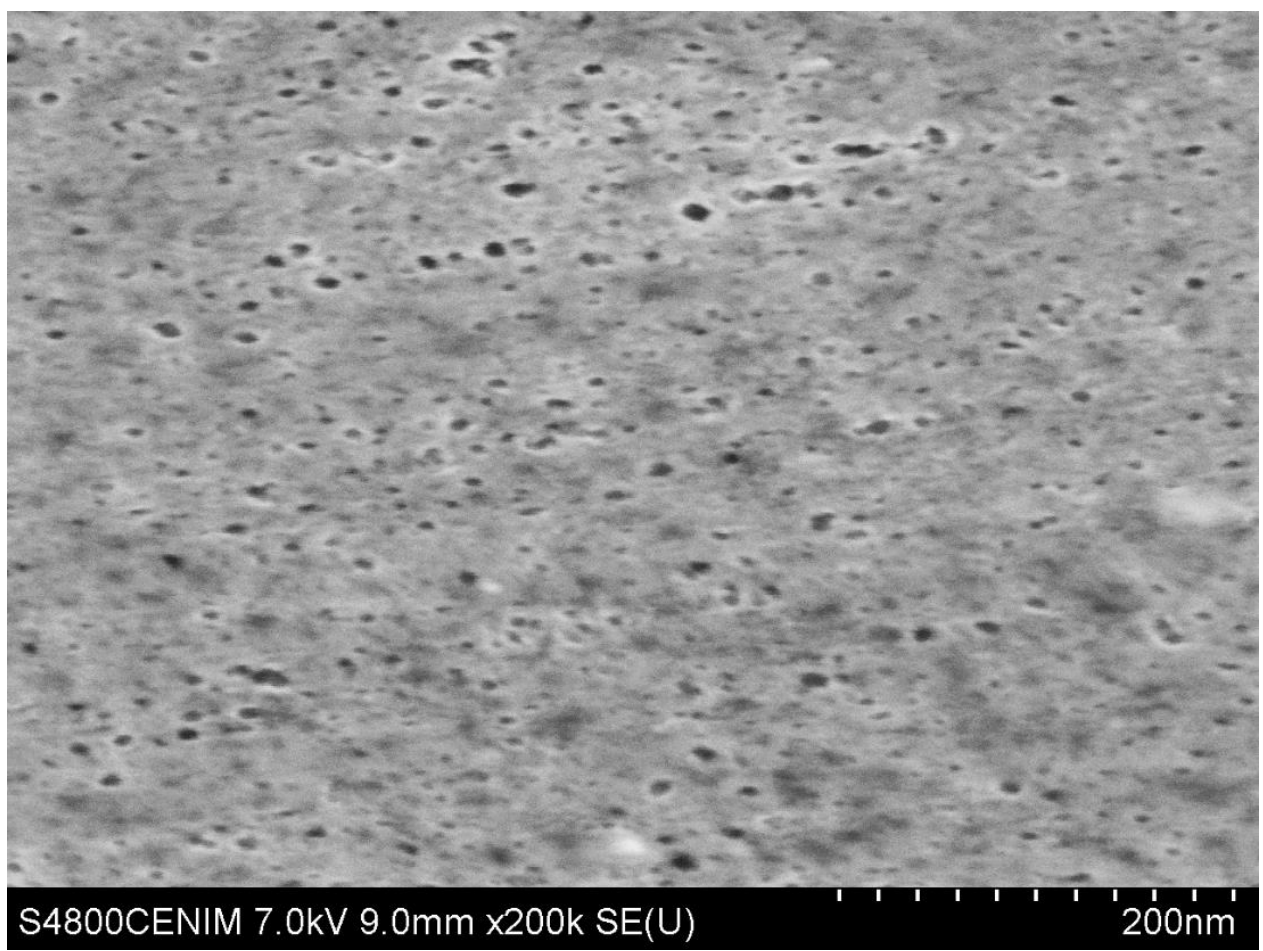

b)

Figure 5 

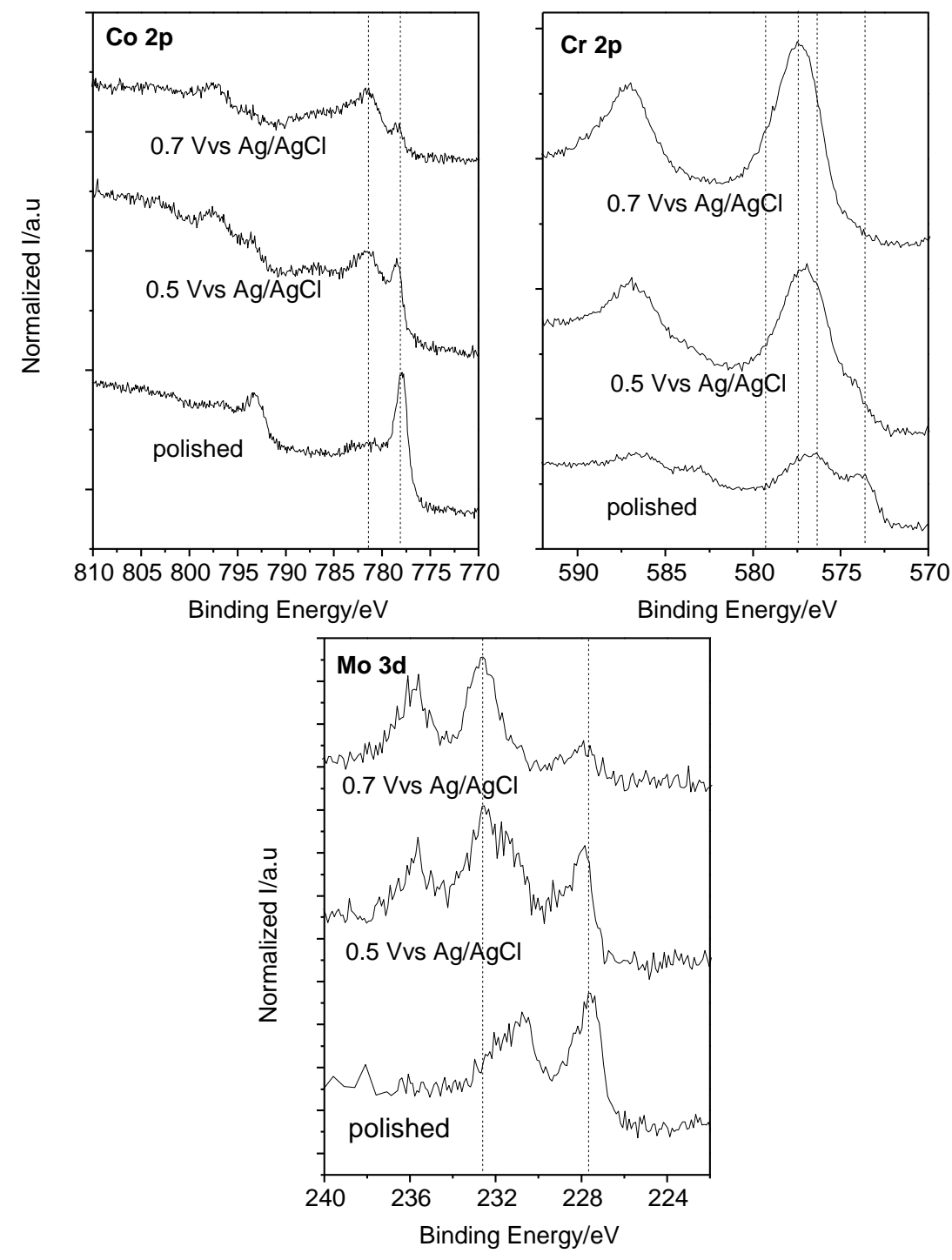

Figure 6 

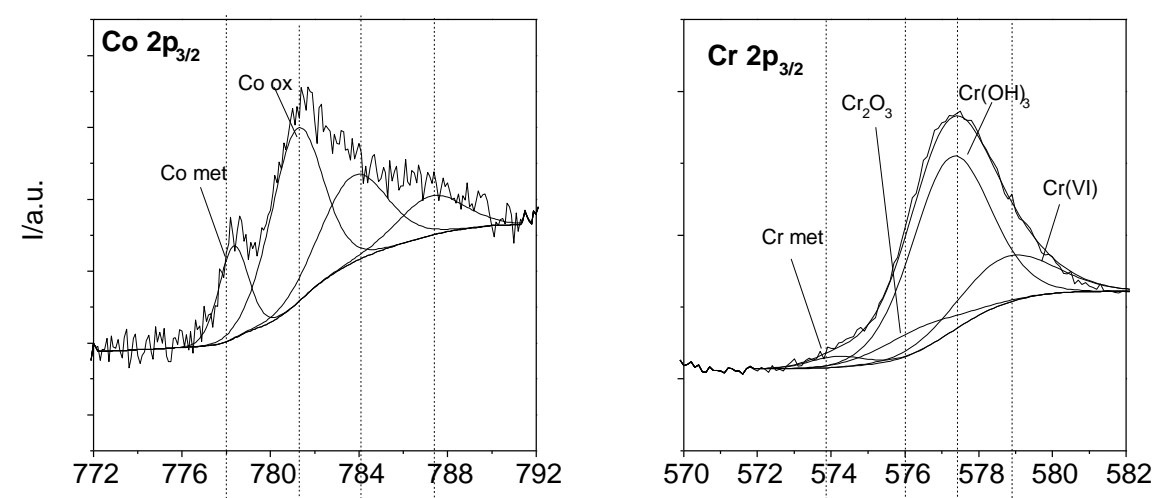

$0.7 \mathrm{Vvs} \mathrm{Ag/AgCl}$
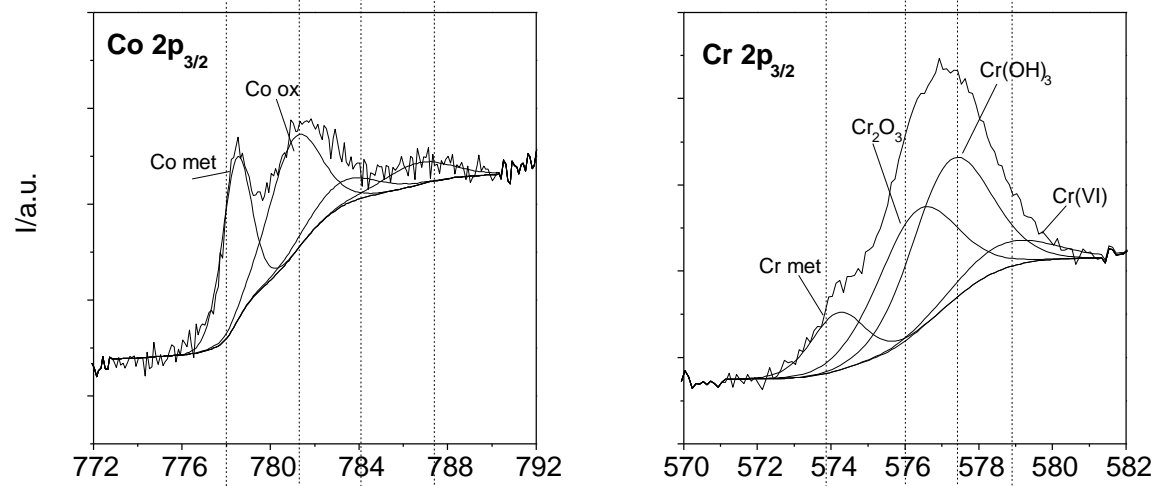

$0.5 \mathrm{Vvs} \mathrm{Ag} / \mathrm{AgCl}$
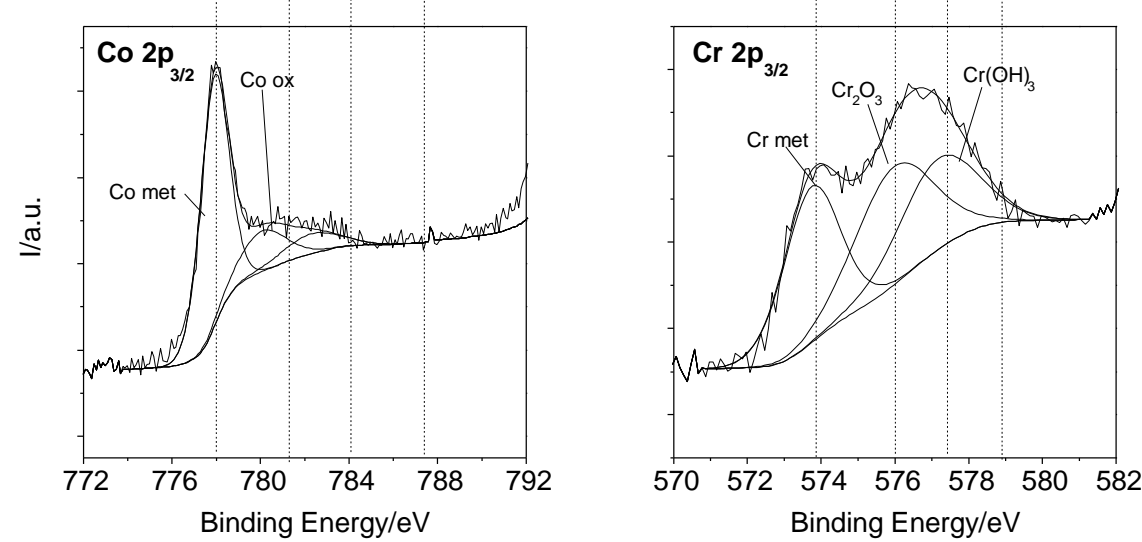

Polished

Figure 7 


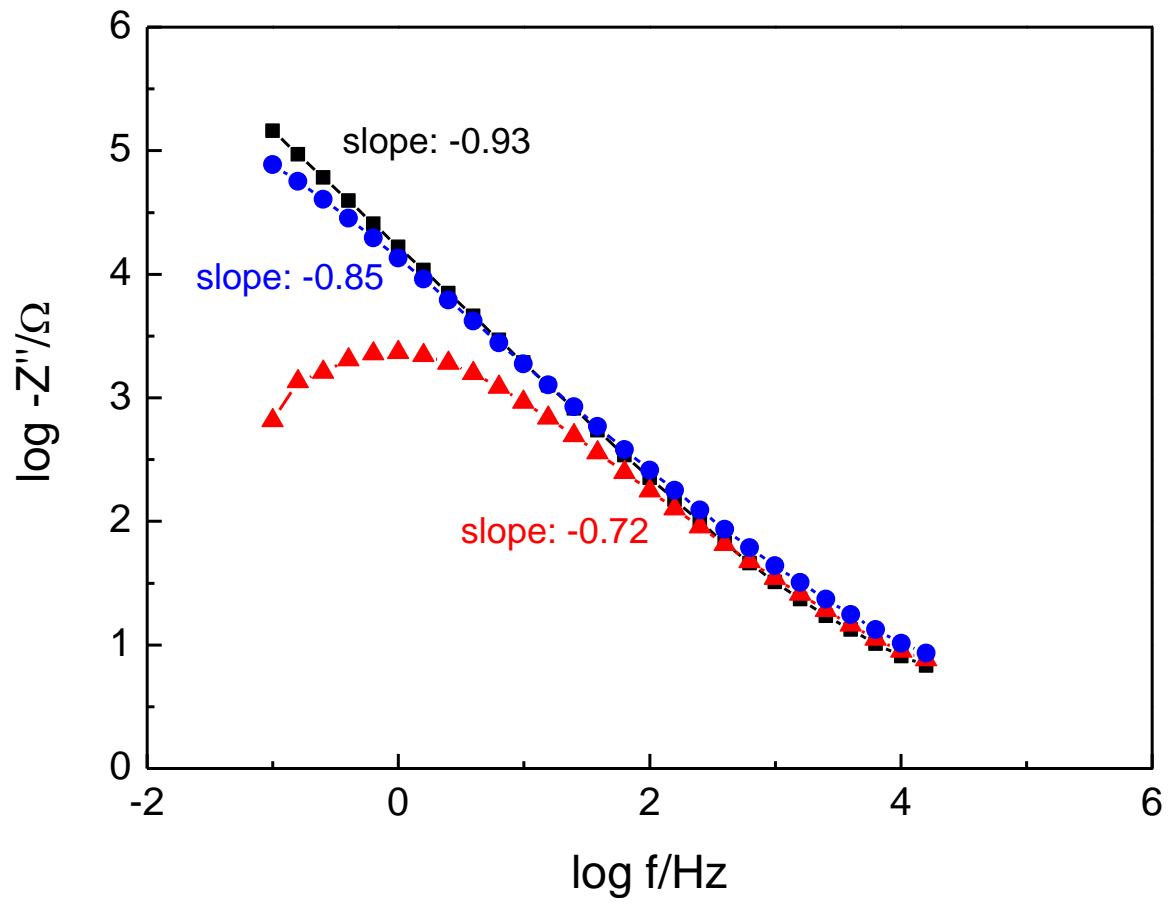

a)

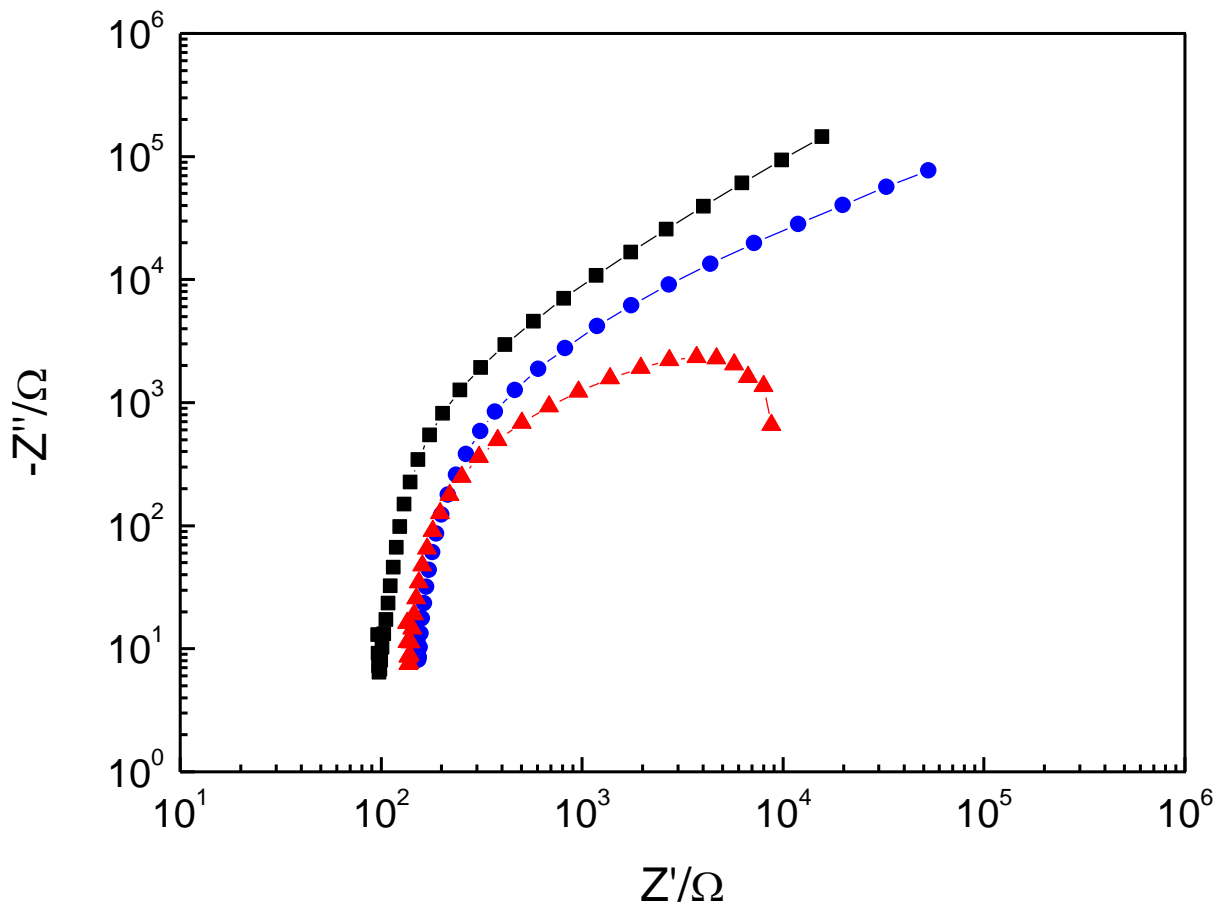

b)

Figure 9 


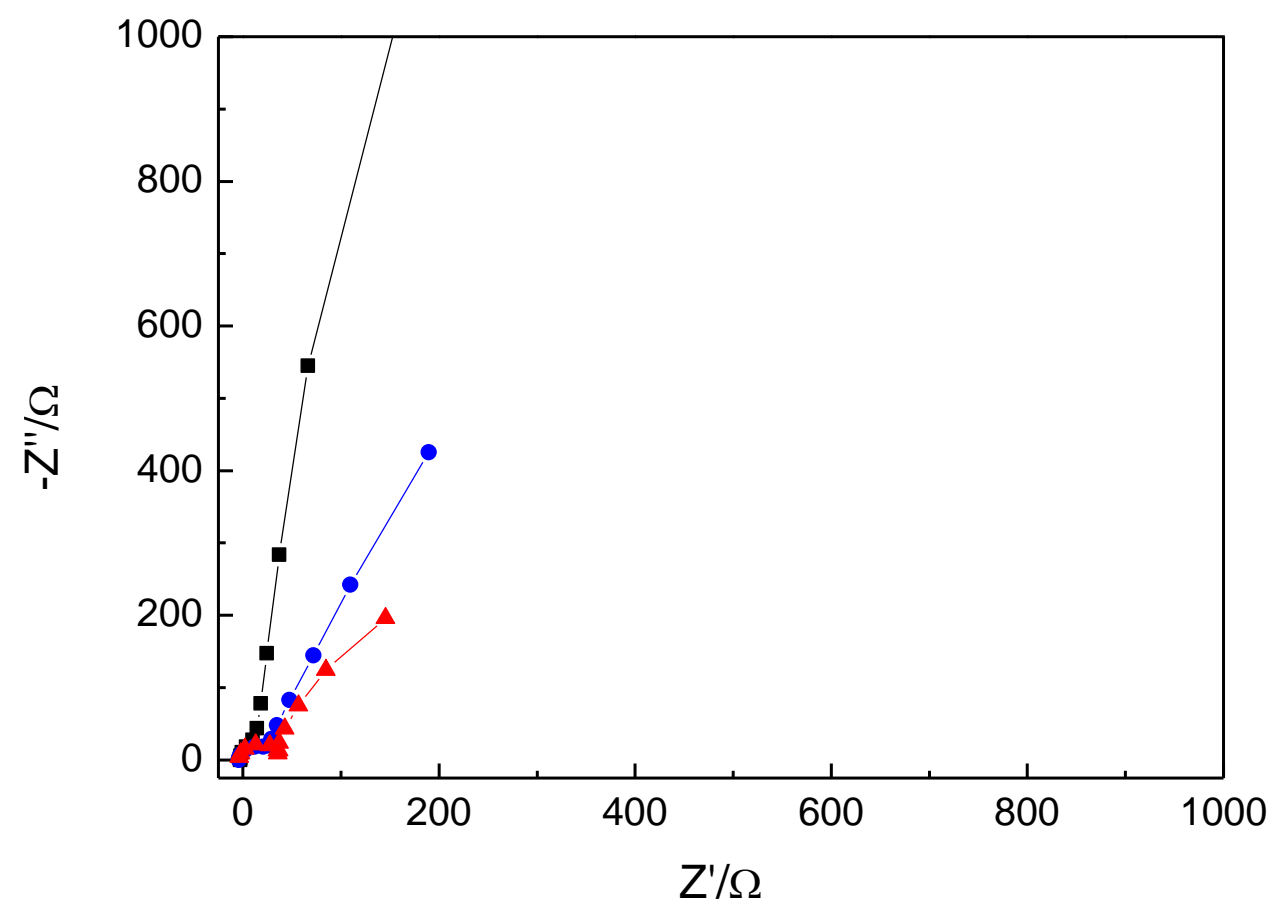

Figure 10 


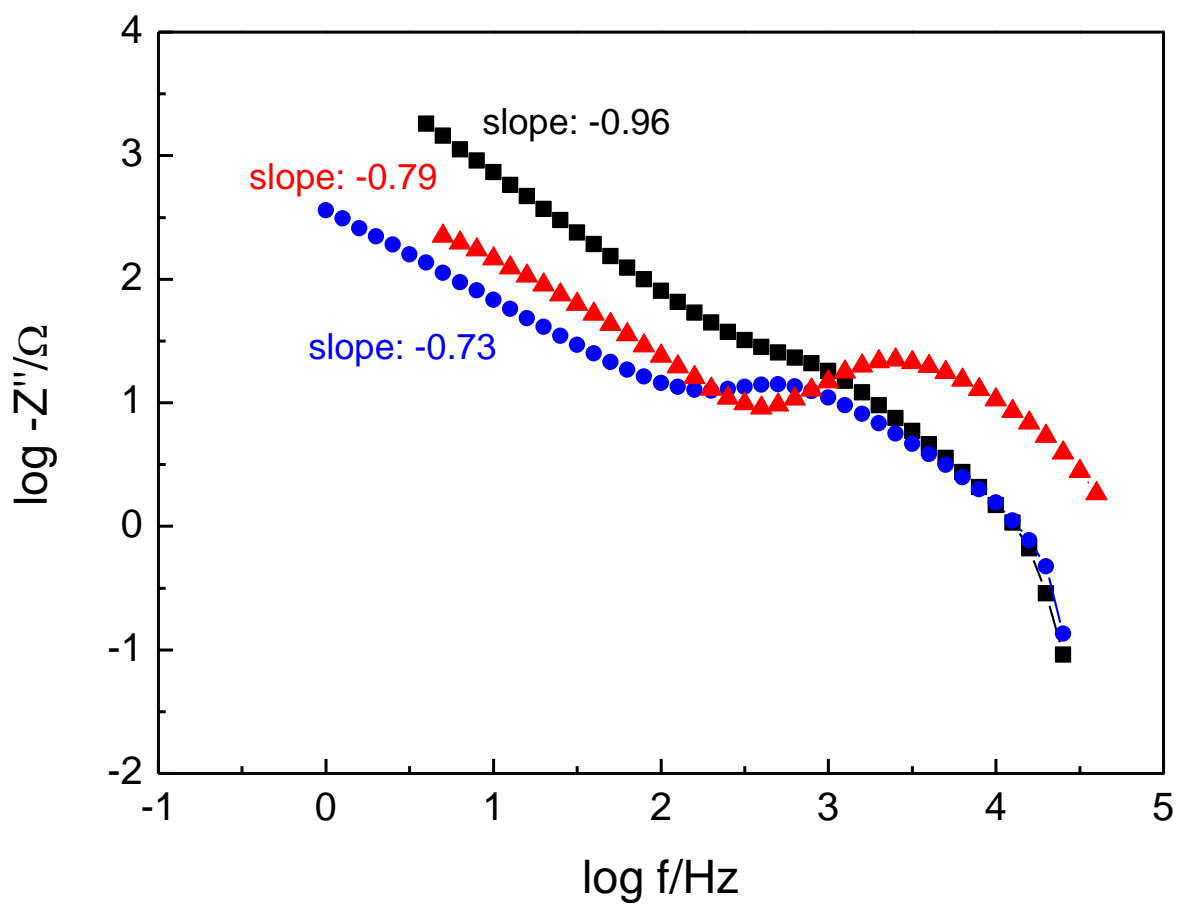

Figure 11 